Gastroscopy will also be of great use in watching cases that have been operated on and in detecting recurrence. Chronic incurable ulcers of the stomach may be examined with reference to the presence of carcinomatous degeneration, and the many cases of cicatricial stenoses in the pylorus may be investigated. The position of an ulcer in the stomach for which excision is contemplated may be ascertained. Hour-glass contraction of the stomach may be diagnosed with certainty, and chronic catarrh of the stomach with impairment of its motility may be distinguished from carcinoma. Ulcer and stenosis of the duodenum may also be distinguished from the corresponding morbid conditions in the stomach. Furthermore, gastroscopy enables a differential diagnosis to be made in a great number of abnormal states which simulate organic disease of the stomach; these are the so-called pseudo-diseases of the stomach (Oser), and are neuroses imitating the symptoms of ulcer, \&c. A knowledge of the position of an ulcer of the stomach is sometimes of the utmost consequence for its surgical treatment, and exploratory laparotomy does not always answer the purpose, for inspection of the serons surface of the stomach is not decisive as to lesions in the interior. Finally, the rare cases of foreign bodies in the stomach, such as balls of hair and lumps of shellac, may be distinguished from tumours.

It is unquestionable that an experienced surgeon who knows upon what morbij process and upon what spot he must direct his attention will be more successful in gastroscopy than an inexperienced surgeon. Gastroscopy is no doubt the most difficult of endoscopic procedures. For proficiency much practice is essential and it does not suffice to make use of it only now and then. It is true that œsophagoscopy requires still more experience for the correct interpretation of the appearances observed. The best plan for a learner is to begin by practising with a model (phantom) of the stomach. The method of introducing the apparatus is in the next place learnt by trials on bodies of the recently deceased, the gastroscope being placed in an indiarubber tube closed at the bottom. Every opportunity should be taken of seeing pathological conditicns in the recent state at operations. Whoever uses the apparatus must understand every detail of its mechanical construction and must be perfectly familiar with its management; he must also possess a delicate tactile sense for sounding, and must be able instantly to form an opinion regarding the appearances observed. I am confident that in a few years gas roscopy will gain ground, as cesophagoscopy has already done, and that excellent results will be obtained by well-trained specialists.

'Dresden.

\section{A CASE OF PERNICIOUS ANÆMIA TREATED BY ANTI-STREPTO- COCCIC SERUM.}

BY WILLIAM ELDER, M.D., F.R.C.P. EDIN., PHYSICIAN TO LEITH HOSPITAL.

IN THE LANCET recently ${ }^{1}$ Dr. William Hunter placed before the profession the results of his most recent investigations into the causes and symptoms of pernicious anæmia. The conclusions he has arrived at are best described in his own words as given in the last part of his paper. Dr. Hunter states: "The definition I formulate for the disease is, then, the following. Pernicious anæmia, a chronic infective disease localised to the alimentary tract; caused by a definite infection of certain parts of the mucosa of the alimentary tract, chiefly of the stomach, occasionally also of the mouth and of the intestine. It is characterised by (1) intermittent destruction of blood and increasing anæmia (and all the other pathological and clinical changes consecutive to these-e.g., anæmia, lemon colour, urobili. nuria, hæmorrhages, dyspnœa, palpitation, œdema), as the result of the absorption of poisons into the blood; (2) periodic disturbance of the alimentary tract, chiefly of the stomach and the intestine, as local effects of the infection

1 The Lancet, Jan. 27 th (p. 221), Feb. 3rd (p. 296) and 10th (p. 371), 1900.

2 The Lancet, Feb. 10th, 1900, p. 374 on the alimentary canal ; and (3) occasional 'toxæmic' attacks characterised by fever, sweatings, general nervous symptoms; not infrequently by effects-e.g., numbness, tingling, ataxia, absence of reflexes-denoting deeper nervous changes, such as peripheral neuritis, sclerosis of the cord."

I need hardly point out how important these conclusions are, if further investigations confirm them, for a successful treatment of the disease. The first part of Dr. Hunter's elaborate article appeared in THE LANCET of Jan. 27th, and it so happened that the following case was admitted to Leith Hospital under my charge on the same day. The reading of the first part of the article led me to begin the treatment of the case on the same lines as he suggested in the third part which appeared in THE LANCET of Feb. 10th. Briefly, that treatment consisted in the thorough cleansing of the mouth with antiseptic mouth-washes, the administration of internal antiseptics in the form of salol and salicylate of bismuth, and the injection of anti-streptococcic serum. For the notes of the case, as well as for the carrying out of the treatment, I am indebted to the house physician at Leith Hospital, Miss Edith Hudson, M.B. Edin.

A man, aged 35 years, was admitted to Leith Hospital on Jan. 27th, 1900, complaining of debility and breathlessness. The history of his present illness was as follows. About six months before (in July, 1899) the patient had a severe attack of sickness and diarrhoa, and since then he had felt that he was gradually getting weaker and he had had occasional attacks of sickness. About the end of the following November he had what he called a "chill," which seems to have been a slight feverish attack. After this left him he felt more debilitated than ever. It tired him to walk short distances and he began to be very breathless. About the first week in December he first noticed that his skin was of a pale yellow tinge and he became troubled with constipation. For a month or two before he came under treatment he had had very slight bleeding piles, but he had never lost much blood, only a streak having been detected very occasionally. He continued to work till three weeks before admission and was then forced to stop owing to his weakness. He attended at the hospital as an out-patient for ten days before his admission. He had not previously had any definite illness, but he occasionally suffered from pain along the costal margin on both sides which was, he said, very slight, and he sometimes had "bilious attacks." About 17 years ago be was troubled very much with bad teeth, had many gumboils, and had to get several teeth extracted. Since then his teeth had been bad and had troubled him much, but gum. boils had not been so frequent. His mother, father, and the other members of the family were strong and healthy.

Siate on admission. - The patient was found to be g markedly anæmic man. His skin was of a lemon yellow colour. The palpebral conjunctiva and the mucous membrane of the mouth were very pale and the ocnlar conjunctiva was slightly yellow. He had a rigor shortly after admission, was breathing very rapidly, and was almost pulseless. The temperature was $100.8^{\circ} \mathrm{F}$. The pulse improved after he was given an ounce of whisky and five minims of digitalis, and it was 124 about half an hour after admission. With regard to the hæmopoietic system the spleen was not enlarged. The blood was examined on Jan. 29th, two days after admission, and showed hæmoglobin 24 per cent., red corpuscles 797,500 , and white corpuscles 4520 . As to the integumentary system the skin had a soft velvety feel and was of a yellow lemon tint, except over the lower part of the back, where it was brownish in colour, the discolouration being diffused and not in circumscribed patches. With regard to the circulatory system he had palpitation and shortness of breath on exertion If working with his head low he felt very giddy. $\mathrm{He}$ was occasionally troubled with tinnitus aurium. The cardiac impulse was neither visible nor palpable. On percussion the base was at the upper border of the third rib and the right border reached to the right edge of the sternum. The left border was three and a half inches from the mid-sternum. Auscultation detected nothing abnormal about the sounds. The pulse was 124 per minute it was large, soft, and easily compressible. As to the alimentary system the tongue was pale, flabby, and indented by the teeth. The lips and the mucous membrane of the mouth were pale. Many of the teeth were in a state of decay and there were a number of carious stumps. The appetite was fairly good and the thirst was not increased. The patient sometimes suffered from pain along the left 
costal margin and a burning sensation in the stomach. These sensations had no reference to food. The bowels were very constipated. The stomach was not enlarged. Liver dulness extended to about an inch above the costal margin. With reference to the nervous system, on rising after sitting for any length of time be felt giddy and his limbs were very tremulous when he walked. He complained of seeing dark specks before his eyes and occasionally he saw yellow and red lights floating in the air, the red being close before his eyes and the yellow at a distance. His temper was rather irritable. He had not been sleeping very well for some time. On ophthalmoscopic examination nothing abnormal could be seen in the retina. The respiratory system showed nothing abnormal. The specific gravity of the urine was 1020. The reaction was acid. There were no abnormal constituents and no indican.

Treatment and progress.-The patient was put on milk diet and was given a febrifuge mixture and half an ounce of whisky every six hours as a stimulant. On the evening of Jan. 27th the temperature reached $103.6^{\circ}$ and the pulse was 120. On the 28 th the temperature was $101^{\circ}$ in the morning and $101.4^{\circ}$ in the evening, and the pulse was 120 . On the $29 \mathrm{sh}$ the temperature was $100^{\circ} 8^{\circ}$ and the pulse was 110 . On the 30 th he was very suspicious and it was very difficult to get him to take his medicines, as he thought that the medical attendants and the nurses were trying to poison him. The tempera. ture on this day was $100^{\circ}$ and the pulse was 108 , and on the 31 st the temperature was $99^{\circ}$ and the pulse was 100 . On Feb. 1st the temperature was down to normal and the pulse was 100 . When the lights were turned down he became very excited; he jumped out of bed and was brought back after a great deal of persuasion. An attempt was made to give him bromide but he absolutely refused to take any drugs. He complained of being hungry, so he was given hot milk with 15 grains of sulphonal dissolved in it. He quieted down after a while and slept better than he had done for several nights. On the 3 rd he was quieter and talked more sensibly. $\mathrm{He}$ was put on convalescent diet. The following treatment was then begun. A powder consisting of five grains of salol and 15 grains of bismuth salicylate was ordered to be taken every six hours. Eight cubic centimetres of anti-streptococcic serum were injected into the subcutaneous tissue below the iliac crest. A mixture of one drachm of tincture of myrrh, 24 grains of carbolic acid, with six ounces of water was ordered as a mouth-wash. The patient's weight was 9 st. $1 \mathrm{lb}$. On the $5 \mathrm{th}$ eight cubic centimetres of anti-streptococcic serum were injected and on the $7 \mathrm{th} 10$ cubic centimetres. An examination of the blood on this day showed hæmoglobin 44 per cent., red corpuscles 1,962,500, and white corpuscles 4700 . On the 9 th five cubic centimetres of anti-streptococcic serum were injected and the patient was allowed to be up. On the 11th his skin was seen to be not so yellow as it had been. He bad lost about two and a half pounds in weight, now weighing 8 st. $12 \frac{1}{2} \mathrm{lb}$. The serum running short he had not an injection on this day as was intended. On the 13 th 10 cubic centimetres of anti-streptococcic serum were injected and the examination of the blood showed hæmoglobin 66 per cent., red corpuscles $2.340,000$, and white corpuscles 4500. 10 cubic centimetres of anti-streptococcic serum were again injected on the 15 th and the same quantity again on the 17 th, on which day the patient was taking his food well; he had been having very good nights. On the 19th he again received 10 cubic centimetres of anti-streptococcic serum. Daring the week the patient had lost one and a half pounds in weight and now weighed 8 st. $11 \mathrm{lb}$. On the 21st 10 cubic centimetres of anti-streptococcic serum were injected. He had been restless during the previous night and very wakeful, and 10 grains of trional were administered. On the 23rd 10 cubic centimetres of anti-streptococcic serum were injected. The blood was examined and showed hæmoglobin 66 per cent., red corpuscles $3,355,000$, and white corpuscles 5100 . On the 25th his weight was the same as that of a week ago. He was very costive and was therefore ordered a drachm of liquid extract of cascara sagrada to be taken at bedtime. On the 26th and 28th 10 cubic centimetres of anti-streptococcic serum were injected. The blood was examined on the latter day and showed hæmoglobin 90 per cent., red corpuscles $3,700,000$, and white corpuscles 5100 . On the night of March 2nd he was sleepless and very excited. He talked a lot of nonsense and said he felt as if he had very little blood in his body, and that the little blood he had was leaving him from the tips of the fingers, and so on. 15 grains of trional were given on the 3 rd and he slspt a little after its administration. He still weighed $8 \mathrm{st} .11 \mathrm{lb} .10$ cubic centimetres of anti-streptococcic serum were given on the $4 \mathrm{th}$. On the $6 \mathrm{th}$, as he had been restless and wakeful during the night, he was given 15 grains of trional dissolved in hot milk, and 15 grains of trional were again given on the night of the 6th. 10 grains of anti-streptococcic serum were injected on the 8th. He had been quiet on the previous night and had slept well without any hypnotic. He talked of blood running up the back of his head and rushing down the bridge of his nose. His wife was asked if he had been quite sensible in his conversation when he was at home, and she said that after the beginning of his illness he used to imagine that all sorts of queer things were going on inside him. An examination of the blood on the 10 th showed hæmoglobin 88 per cent., red blood corpuscles $4,360,000$, and white corpuscles 4500 . On the 12 th it was found that he had gained two and a balf pounds in weight during the previous week. He had been given 15 grains of bromide of potassium at midnight on the 11th. 10 cubic centimetres of anti-streptococcic serum were given on the 12th and again on the 15th, when he looked remarkably well, the skin having a perfectly healthy colour and appearance. He had another of his wakeful and excitable nights on the 18th and was again given 15 grains of bromide of potassium at 1030 P.M. 10 cubic centimetres of anti-streptococcic serum were also injected. It should be said here that all the serum injections were given in the subcutaneous tissues covering the dorsum ilii. He had no constitutional symptoms after them. On several occasions the urine was examined and no trace of albumin was found. On the 20 th an examination of the blood showed hæmoglobin 104 per cent. and red corpuscles $4,800,000$. He had no anti-streptococcic serum injected after the 19th. On the 26 th he continued to look and to feel well, and he slept very well. He still spoke, however, about queer sensations in different parts of his body, but his talk was more sensible.

The blood examinations were kindly made by Dr. J. S. Fowler, assistant physician to Leith Hospital, and the following are his reports on two examinations. The first describes the appearance of the blood on admission and the second its appearance on March 10th. "Jan. 29th.Red corpuscles 797,500, leucocytes 4520, hæmoglobin 24 per cent. The red corpuscles show marked alterations; megalocytes are numerous and many of them have no central dell. On the whole the average diameter of the red corpuscles is above the normal. There are numerous poikilocytes as well as fairly well-marked polychromatophilia. There are a great many nucleated red corpuscles; by comparison with the number of leucocytes in the films they may be estimated at about $1 C 88$ per cubic millimetre. Typical normoblasts are comparatively few, the majority of the cells being of the megaloblastic type but somewhat smaller in size than usual. 31 per cent. of the nucleated reds are typical megaloblasts. A few nucleated reds show mitotic figures. The differential count of the leucocytes gives - large and small mono-nuclear 30 per cent., polymorphonuclear 66.5 per cent., eosinophile 3 per cent., myelocytes about 0.5 per cent. March 10 th. - Red corpuscles $4,360,000$, leucocytes 4500 , hæmoglobin 88 per cent. The red corpuscles appear almost normal though some megalocytes are still present. Nucleated reds are exceedingly few, only one or two normoblasts being found. Leucocytes : large and small mono-nuclear 40 per cent., polymorpho-nuclear $55^{\circ} .5$ per cent., eosinophiles 4 per cent., myelocytes about 0.5 per cent."

When one considers how unsatisfactory the treatment of cases of pernicious anæmia has been in the past I make no apology for thus early recording the results obtained in this interesting case. Dr. Hunter, who has done so much in his investigations on this disease carried on for many years, has arrived at the conclusion that the anæmia which is such a characteristic symptom is only a symptom and is a result of an infection of the alimentary tract. I do not at this time intend entering into a full discussion of the evidence which he has so ably brought forward in support of his conclusions, but this case is one which, apart altogether from the result of the treatment, might be used by him to further support his views. Dr. Hunter believes that the disease has its origin in the swallowing of pyogenic organisms which, when long continued, leads first to gastric or intestinal catarrh and, secondly, to a specific infection of the gastric or intestinal mucous membrane with, as a result, a hæmolysis in the portal circulation, so that all the 
symptoms of pernicious anæmia show themselves. He suggests that probably the specific infection of the gastric mucous membrane is of "mixed" origin due to more than one organism, and that in most cases the primary source of the organism is to be found in the mouth associated, as a rule if not invariably, with bad teeth. Dr. Hunter also suggested that serum treatment might be tried, and as streptococci are found in a large proportion of cases of caries of the teeth of stomatitis, and of gastritis, be intended trying treatment by anti-streptococcic serum.

There are some special points I would like to discuss in connexion with the case.

Diagnosis.-Was this a case of pernicious anæmia? To my mind there can be little doubt about the diagnosis. The patient had not been observed longer than a week before his admission, but his condition when admitted was so characteristic of pernicious anæmia that the disease was at once suggested to the minds of those who saw him. His pale lemon yellow colour at once indi. cated the marked anæmia which was present without apparently a sufficient cause. After careful questioning we could only get a history of blood-stained stools on one or two occasions which apparently came from a small hæmorrhoid. This loss of blood, however, should hardly be designated by the word "hæmorrhage," for it was trivial and at rare intervals. I only mention it in order to be absolutely accurate in the recording of the case. I am thoroughly satisfied that it had nothing whatever to do with his symptoms. In addition to the colour the other symptoms - breathlessness, general weakness, \&c.-all pointed to marked anæmia, but when a microscopic examination of his blood was made the diagnosis became more certain. He was admitted on Jan. 27th and it was found that he had 797,500 red corpuscles per cubic millimetre instead of $5,000,000$, that his hæmoglobin was 24 per cent. of normal, and that his leucocytes were 4520 per cubic millimetre. His corpuscles, besides, showed the characteristic appearances which are supposed to be associated with pernicious anæmia. Such profound anæmia is seldom found in men unless after severe hæmorrhages, and the fact that although the red corpuscles were reduced to less than a sixth of what they ought to be, whilst the hæmoglobin was on'y reduced about one-fourth of the normal with little reduction in the leucocytes, points strongly to the case being one of pernicious anæmia and not one of anæmia from loss of blood or such an anæmia as one sees in chlorosis. The microscopic appearances of the corpuscles were all typical of the disease. The progress of the case as regards the microscopic appearances of the blood points strongly in the same direction, because a marked characteristic which was brought out by all the examinations was the greater reduction in the red blood corpuscles than in the hæmoglobin, winilst the leucocytes remained practically the same. As the case improved the appearances of the corpuscles became less typical of the disease. His other symptoms tend to confirm the diagnosis. Marked features in the case were the nervous symptoms, chiefly evidenced in the sleeplessness, general irritability, and varying subjective sensations, which were chiefly referred to the abdominal region and digestive organs. Disturbances of the nervous system are often prominent symptoms in this disease. It was difficuit to ascertain from his history how long he had shown these nervous symptoms and whether he might not have had some symptoms of mental or intellectual weakness before the onset of his anæmia. The patient was perhaps best described as being "slightly peculiar" at times, but this peculiarity was generally not at all well marked, though at other times it was quite evident. These symptoms did not improve in proportion to the improvement in the condition of the blood and this fact makes me a little doubtful as to whether they were all due to his disease and not rather to a slight mental degradation which he had had before the onset of his illness. The serum and other treatment I believe have no causal relation to those symptoms, as they were quite marked on his admission, and there was a history of them for at least some time previously. As regards the primary cause of the disease this case supports Hunter's views. The mouth and teeth could be described as in a state of neglect. A large number of teeth were carious and many were reduced to mere stumps, and he gave a distinct history of having had frequent gum-boils. The history of discharge of pus into the mouth extended back for many years. He had a history of occasional bilious attacks during the previous six months with pains referred to the costal margin, pointing to gastric disturb. ance, for some time before the onset of his anæmia, and he gave a history of having suffered from an attack of diarrhcea at the onset of his gastric symptoms. These gastric and intestinal disturbances are therefore also in accordance with Hunter's theory of the cause of the disease.

Treatment.-As regards the treatment of the case the details are sufficiently noted in the notes which $I$ have already given. The treatment was begun on Feb. 3rd, exactly a week after the patient's admission into the hospital. His mouth was thoroughly washed and brushed with an antiseptic mouth-wash and he was given five grains of salol and 15 grains of salicylate of bismuth internally every six hours. 10 grains of anti-streptococcic serum were at first injected into the subcutaneous tissue over the dorsum. ilii every second day. At the first two injections, on account of a fault in the syringe, he received only about eight cubic centimetres, but afterwards 10 cubic centimetres were given on each occasion except on Feb. 9th, when be got only five cubic centimetres. From Feb. 3rd till March 19th he received in all 18 injections of the serum. and the antiseptic treatment was continued all through. With the exception of a hypnotic occasionally when his nervous symptoms required it and a dose of castor oil or cascara sagrada for his constipation this was the only medicinal treatment. He got none of the usual remedies for anæmia-neither iron nor arsenic nor bone-marrow. His blood was examined at intervals of about a week and the result is noted in the following table. The treatment, it should be said, began on Feb. 3rd.

\begin{tabular}{|c|c|c|c|c|}
\hline \multicolumn{2}{|l|}{ Date. } & \multirow{2}{*}{$\begin{array}{c}\begin{array}{c}\text { Red } \\
\text { corpuscles. }\end{array} \\
797500\end{array}$} & Hæmoglobin. & \multirow{2}{*}{$\begin{array}{c}\text { Leucocytes } \\
4520\end{array}$} \\
\hline Jan. 29th ... . & $\begin{array}{ll}\ldots & \ldots\end{array}$ & & 24 per cent. & \\
\hline Feb. 7 th $\ldots$. & $\ldots \quad \ldots$ & $1,962,500$ & 44 & 4700 \\
\hline , 13th... . & $\ldots \quad \ldots$ & $2,340,000$ & 66 & 4500 \\
\hline , 23rd ... . . & $\ldots \quad \ldots$ & $3,355,000$ & 66 & 5100 \\
\hline , 28th ... . . & $\ldots \quad \ldots$ & $3,700,000$ & 90 & 5100 \\
\hline March 10th & $\ldots \quad \ldots$ & $4,360,000$ & 88 & 4500 \\
\hline " 20th. & $\cdots \quad \ldots$ & $4,800,000$ & 104 & - \\
\hline
\end{tabular}

On March 20th (52 days after his admission and 45 days after the commencement of treatment) bis blood had practically reached normal. ${ }^{3}$

It would be a mistake to draw very decided conclusions from the results obtained by the serum treatment of one case, the more especially as cases of pernicious anæmia are so apt to be intermittent-a fact which almost every practitioner who has had experience of such cases must soon bave noted. If a new method of treatment is adopted in those cases we are apt to think that the particular treatment has been the cause of the improvement. The hopes of the profession bave been raised again and again with regard to this disease by the announcement of good results from particular forms of treatment. Arsenic and bone-marrow have probably hitherto given the best results, but although improvement has been derived from both forms of treatment in many cases such improvement bas generally been only temporary and the disease as regards its ultimate result has been one of the most hopeless. Whether further experience of antistreptococcic serum will confirm the result I bave obtained in this case or not time alone will enable us to judge. That every case will be benefited by this treatment I can scarcely venture to hope, because the chances are that the disease, even if due to a specific infective affection of the gastric mucosa, may not always be due to the same species of organism and may, as suggested by Dr. Hunter, be owing to "mixed" infection. Judging from the results which have been obtained from the use of the anti-streptococcic serum in other conditions of blood infection and from what is recorded in the medical journals it must be conclnded that this serum is not at all certain in its curative action. Whether this result is due to faulty serum placed upon the market or, as is more probable, to some cases of bloodpoisoning being due to "mixed infection," or to there being

3 On April 3rd an examination of his blood was made. The red corpuscles were found to be 4,325,000, hæmoglobin 104 per cent., and leucocytes 5600. On April 16th he was discharged from hospital and on April 22 nd he reported himself as feeling fit and well and looked in very good health. 
several species of streptococci producing a poison giving rise to similar symptoms but not counteracted by the administration of the anti-streptococcic serum in the market, further experience will show. The case recorded above is suggestive, and I believe this form of treatment is worthy of a further careful trial by those who have cases of pernicious anæmia under their care.

Teith.

\section{ON CYSTS OF THE BREAST, THEIR RELATIVE FREQUENCY, DIAGNOSIS,} AND TREATMENT. ${ }^{1}$

By THOMAS BRYANT, F.R.C.S. ENG., M.CH. R.U.I., CONSULTING SURGEON TO GUY'S HOSPITAL; SURGEON EXTRAORDINARY FO THE QUEXEN

Four years ago, after having seen in consultation a very interesting series of cases of tumour of the breasts which had been considered to be examples of carcinoma but which eventually turned out to be cases of simple cysts, I was induced to write and subsequently to read a paper before this society upon the Diagnosis and Treatment of Early Cancer and Cysts of the Breast, ${ }^{2}$ and I did so under the conviction that the frequency of cyst disease of this gland was not appreciated, that its diagnosis was not as perfect as it ought to be, and that the treatment of such cases was consequently uncertain and unsatisfactory. In that paper I quoted a dozen cases of simple cysts in the breast which had been suspected or pronounced to have been cancerous and which in the majority of instances would have been treated as such, and probably by the removal of the breast, when with a correct diagnosis the cyst itself was dissected out of the affected gland or otherwise destroyed, and the breast was saved in every instance.

The experience I have had since that date, with the attention $I$. have given to the subject since my interest in it was awakened by the compilation of that paper, has led me to review as a whole my clinical experience of breast disease during recent years and particularly as to its bearing upon the frequency of the development of cyst disease of the gland, and $I$ now bring before you in a condensed form the conclusions to which my investigations have brought me, of which the following are the most important: (1) that simple cysts of the breast are far more common than they are generally believed to be ; (2) that they are chiefly found in women during the same period of life as that in which cancer is met with; (3) that they are mostly quite amenable to local treatment without the sacrifice of the breast-gland in which they are situated; and (4) that there is no reason to believe that women who have these cysts are more prone to cancer than those who have them not.

With the view of gaining some definite information as to the frequency of the presence of these cysts $I$ have gone to my own note-books and have carefully noted and analysed 242 consecutive cases of breast disease as they have appeared before me in private practice, for $I$ felt convinced that it was by such means alone that a correct impression as to the comparative frequency of the affection was to be acquired. The analysis of these 242 cases comes out as follows: 163 cases were registered as solid tumours or examples of cancer or sarcoma and 67 cases as of cystic disease. Of the 12 remaining cases eight were examples of adenomata, two were cases of lipomata developing in the parts covering the breast, and two were cases of carcinoma in men; but these 12 cases are not now under consideration. It will thus be seen that there are 230 cases of breast disease to deal with-163 of diagnosed cancer or sarcomatous disease and 67 of diagnosed cystie disease, the latter or cystic disease bearing to the former or cancerous disease the relative proportion of $29 \cdot 1$ to 70.9 per cent. These facts suggest the conclusion that out of every four cases of tumour of the breast, more or less simulating cancer, one at least will be of a cystic or simple nature.

Bat it will be said that there is some fallacy in this conclusion, since, in both groups, cases which have been only

1 A paper read before the Medical Society of London on April 23rd, 1900.

2 Transactions of the Medical Society of London, 1896 ; THE LANCET, Feb. 8th, 1896, p. 343. diagnosed are mixed with others in which the diagnosis was proved by operation; and the force of this objection I fully admit. Consequently to get rid of this source of fallacy I have eliminated from my calculation all the cases in both groups which were simply diagnosed and $I$ now give an analysis of the cases of both groups which were subjected to proof by operation. By this method a like conclusion will have to be drawn, for it appears that out of the 163 cases of diagnosed cancer 126 were operated upon, and out of the 67 examples of diagnosed cyst disease 44 were operated upon, the total number of operations being 170 , and these figures work out to show that of the whole number 258 per cent. were examples of cyst disease and $74 \cdot 1$ per cent. of cancerous disease, the proportion of cases being practically the same as in the larger figures, both series supporting the conclusion that ont of every four cases of breast disease more or less simulating cancer one will prove to be an example of cyst disease. These figures consequently fully prove the truth of the first conclusion I have formulated - "that simple cyst disease of the breast is far more common than is generally believed."

I will now proceed to show you the truth of the second conclusion, "that these cases of cyst disease of the breast are found in women at the same period of life as that in which cancer is met with," and for this purpose have analysed all the cases which have presented themselves to me, 67 in all, 23 of which were in single and 44 in married women. The analysis is as follows:-

\begin{tabular}{|c|c|c|c|c|c|c|c|c|}
\hline & \multirow[b]{2}{*}{ Age. } & \multicolumn{3}{|c|}{$\begin{array}{l}\text { Cases operated } \\
\text { upon. }\end{array}$} & \multicolumn{3}{|c|}{$\begin{array}{l}\text { Cases not } \\
\text { operated on. }\end{array}$} & \multirow{2}{*}{ 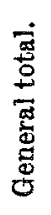 } \\
\hline & & $\begin{array}{l}\stackrel{9}{80} \\
\stackrel{80}{0}\end{array}$ & 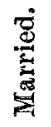 & 吾 & $\begin{array}{l}\stackrel{\infty}{b 0} \\
\stackrel{D}{0}\end{array}$ & 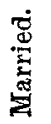 & 㑒 & \\
\hline Under 3 & years of age... & 2 & 1 & 3 & 1 & - & 1 & 4 \\
\hline Between & 31 and 40 & 4 & 4 & 8 & 1 & 2 & 3 & 11 \\
\hline & $41,, 50$ & 8 & 11. & 19 & 4 & 10 & 14 & 33 \\
\hline & 51,60 & 2 & 11 & 13 & - & 3 & 3 & 16 \\
\hline Over 60 & $\begin{array}{llll} & \ldots & \ldots & \ldots\end{array}$ & 1 & - & 1 & - & 2 & 2 & 3 \\
\hline Tota & $\begin{array}{llll}1 & \ldots & \ldots & \ldots\end{array}$ & 17 & 27 & 44 & 6 & 17 & 23 & 67 \\
\hline
\end{tabular}

By this table it appears that out of 44 cases of cysts of the breast in which the diagnosis was confirmed by speration 11 occurred in women under 40 years of age and 33 in women over 40 years of age; and out of 23 cases diagnosed but not proved to be examples of the same affection four were under and 19 were over 40 years of age, the conclusion being that 52 of the whole number of 67 cases, or 77.5 per cent., took place in women over 40 years of age, the proportion in the group of cases which had been operated upon and in that in which the cases had been only diagnosed being about the same. These facts are enough for me to say that they afford ample proof of the second conclusion I have formulated, that these cases of cyst disease of the breast are found in women at the same period of life as that in which cancer is met with.

The third conclusion I have now to support is " that these simple cysts of the breast are mostly amenable to local treatment without the sacrifice of the breast gland in which they are situated," for by a free incision through the soft tissues which cover the cysts they can be exposed and emptied and by a simple dissection removed from the gland. Should the cyst when exposed present a lining membrane absolutely free from anything like papillary or other growths its excision is not, however, a necessity, for when its inner surface has been destroyed by swabbing it with either pure liquid carbolic acid, a strong solution of zinc chloride, or the tincture of iodine there is but little probability that any growth will subsequently appear. In my own practice I have had no instance in which this took place, although when any intra-cystic growth, however small, is found in the cyst wall the dissection of the cyst out of the gland should be adopted as a rule of practice. Indeed, when any suspicious growth is found to exist in a cyst, and such a growth is of a fleshy and not of a papillary nature, the lobe of the breast involved or the whole gland should be taken away according to circumstances, the latter course being probably the safer. But such cases as these have been 